\title{
Ecological Risk Assessment of Jarosite Waste Disposal
}

\author{
Mihone Kerolli-Mustafa, ${ }^{a}, *$ Lidija Ćurković, ${ }^{b}$ Hana Fajković, ${ }^{c}$ and Sanda Rončevićd \\ ${ }^{a}$ Department of Environmental Management, International Business College Mitrovica, 40000 Mitrovica, Kosovo \\ ${ }^{\mathrm{b}}$ Department of Materials, Faculty of Mechanical Engineering and Naval Architecture, \\ University of Zagreb, Ivana Lučića 1, 10000 Zagreb, Croatia \\ 'Department of Geology, Faculty of Science, University of Zagreb, Horvatovac 102A, 10000 Zagreb, Croatia \\ ${ }^{\mathrm{d}}$ Department of Chemistry, Faculty of Science, University of Zagreb, Horvatovac 102A, 10000 Zagreb, Croatia
}

RECEIVED NOVEMBER 10, 2014; REVISED MAY 11, 2015; ACCEPTED MAY 29, 2015

\begin{abstract}
Jarosite waste, originating from zinc extraction industry, is considered hazardous due to the presence and the mobility of toxic metals that it contains. Its worldwide disposal in many tailing damps has become a major ecological concern. Three different methods, namely modified Synthetic Precipitation Leaching Procedure (SPLP), three-stage BCR sequential extraction procedure and Potential Ecological Risk Index (PERI) Method were used to access the ecological risk of jarosite waste disposal in Mitrovica Industrial Park, Kosovo. The combination of these methods can effectively identify the comprehensive and single pollution levels of heavy metals such as $\mathrm{Zn}, \mathrm{Pb}, \mathrm{Cd}, \mathrm{Cu}$, Ni and As present in jarosite waste. Moreover, the great positive relevance between leaching behavior of heavy metals and F1 fraction was supported by principal component analysis (PCA). PERI results indicate that $\mathrm{Cd}$ showed a very high risk class to the environment. The ecological risk of heavy metals declines in the following order: $\mathrm{Cd}>\mathrm{Zn}>\mathrm{Cu}>\mathrm{Pb}>\mathrm{Ni}>\mathrm{As}$.
\end{abstract}

Keywords: ecological risk, jarosite waste, heavy metals

\section{INTRODUCTION}

The deposition of jarosite waste in open tailing dumps is not a liable method because of future environmental cost. Open tailing dumps are exposed to weathering, acid mine drainage and mobilization of metals. There are many documented cases in which the long-term investigation of bioavailability of heavy metals in environment have built up toxic metal concentration in soil, water, air and organisms. ${ }^{1}$ Today, it is widely discussed that the mobility and distribution of heavy metals from solid waste (including mining and industrial waste) depends not only on their concentration but also on their association form. Maximum contamination levels for toxic metals and other inorganic and organic components in soil, water, waste and food chain have been set by different organizations such as: The United States Environmental Protection Agency (US EPA), World Health Organization (WHO), European Union, United States, etc. In order to avoid the environmental problems caused by the disposal and uncontrolled leaching of mining waste, the researchers are making great efforts in developing different cleaner processes. ${ }^{2,3}$ The increase of economic and financial factors dictate that the industry should look forward for development of better opportunities on regard to the recycling or reusing of the industrial hazard waste. In this regard, the researchers in India, China and Italy have intended to produce construction material from jarosite waste. ${ }^{4-7}$ While, other researchers in the frame of sustainable development and waste management intended to recover lead, zinc and precious metals through hydrometallurgical route. This method was considered complex and with high economical cost. ${ }^{8}$ Acid leaching is another effort that was developed by cleaner's processes. The metal ions are mainly associated with or are present in form of organic matter, oxyhydroxides of iron, aluminum and manganese, phyllosilicate minerals, carbonate and sulphides. ${ }^{9}$ In order to determine the chemical form and to evaluate the mobility and bioavailability of trace elements under different environmental conditions the sequential extraction techniques have been developed. ${ }^{10-13}$ In several countries, the problems of contamination with heavy metals are increasing; therefore the application of principal component analysis and risk index method can be very useful tool for assessing the environmental impact of ecological risk of heavy metals in environment. Previous researchers had used several

\footnotetext{
* Author to whom correspondence should be addressed. (E-mail:m.kerolli@ibcmitrovica.eu; mihone_k@hotmail.com)
} 
Table 1. Modified BCR three-step sequential extraction procedure

\begin{tabular}{|c|c|c|}
\hline Extraction step & Solid phase & Extraction procedure \\
\hline F1 & $\begin{array}{c}\text { Exchangeable, } \\
\text { Acid-soluble fraction }\end{array}$ & $40 \mathrm{~mL}$ of $0.11 \mathrm{~mol} / \mathrm{L} \mathrm{CH}_{3} \mathrm{COOH}$, shake 16 hours, room temperature. \\
\hline F2 & Reducible fraction & $\begin{array}{c}40 \mathrm{~mL} \text { of } 0.5 \mathrm{~mol} / \mathrm{L} \mathrm{NH}_{2} \mathrm{OH} \cdot \mathrm{HCl}\left(\mathrm{pH}=1.5,2 \mathrm{~mol} \mathrm{HNO}_{3}\right) \text {, shake } 16 \text { hours at } \\
\text { room temperature. }\end{array}$ \\
\hline F3 & Oxidizing fraction & $\begin{array}{l}5 \mathrm{~mL} \text { of } 8.8 \mathrm{~mol} / \mathrm{L} \mathrm{H}_{2} \mathrm{O}_{2}(\mathrm{pH} 2) \text { shake for } 2 \mathrm{~h} \text { at } 85^{\circ} \mathrm{C} \text {, cool, then } 25 \mathrm{~mL} \text { of } 1 \\
\mathrm{~mol} / \mathrm{L} \mathrm{CH}_{3} \mathrm{COONH}_{4}\left(\mathrm{pH}=2, \mathrm{HNO}_{3} \text { conc.), shake } 16 \text { hours, room temperature. }\right.\end{array}$ \\
\hline F4 & Residual fraction & $\begin{array}{l}\text { The pseudo total minus the three fractions. The pseudo total: digestion in aqua } \\
\text { regia }(3 \mathrm{~mL} \mathrm{HCl}+1 \mathrm{~mL} \mathrm{HNO}) \text {, shake for } 16 \mathrm{~h} \text {. }\end{array}$ \\
\hline
\end{tabular}

methods, such as Geoaccumulation index, Principle component analysis and Set pair analysis to assess soil contamination levels of heavy metals. The Potential Ecological Risk Index (PERI) is a method that is used for the risk assessment of heavy metals. This method was first suggested by Håkanson in 1980 with the aim of indicating the environmental agents and prioritizing contamination studies in lakes and coastal systems. ${ }^{14}$ Although potential risk factor was originally used by Håkanson for the purpose of controlling water pollution, in recent years it was very successfully used for the quality of sediments and soil in the environment with heavy metals. In order to assess the potential risk of heavy metals in lake sediments Håkanson used preindustrial reference levels as background information's, ${ }^{14-17}$ while others used various reference values. ${ }^{7,13-22}$ In general, this method was reported as powerful diagnostic tool for the risk assessment of heavy metals in sediments and soil.

Numerous authors have used the total metal content of heavy metals to determine the assessment of potential risk, while others think that total concentration of heavy metals does not provide the adequate information for assessing the toxicity. Recently, the toxicity of heavy metals was applied after the application of sequential extraction technique by using the concentration of heavy metals in exchangeable fraction. From the ecological point of view the pollution indexes provides useful information to public, decision makers and managers in processing and analyzing the environmental data. ${ }^{17}$

The researchers report that multivariate statistical techniques are the right tool for viewing and analyzing some of complex data. ${ }^{18,19}$ The PCA is one of unsupervised methods that estimate the correlation structure of the variables by finding hypothetical new variables (principal components - PC) that account the variance (or correlation) in a multidimensional data set. ${ }^{19}$ This method helps us to identify simultaneous analysis of several factors and explains the variability of the data during the reduction of a great number of variables to a few unrelated components.
The objective of this study was to assess the ecological risk of deposited waste in Mitrovica Industrial Park, Kosovo through the following work: (i) the total content of $\mathrm{Zn}, \mathrm{Pb}, \mathrm{Cu}, \mathrm{Cd}$, $\mathrm{Ni}$ and $\mathrm{As}$ in jarosite samples in Kosovo; (ii) a modified three-stage chemical extraction of heavy metal fractions and modified Synthetic Precipitation Leaching characteristics of heavy metals (SPLP); (iii) the principal component analysis (PCA) method to establish the correlations between speciation and leaching characteristic of heavy metals; (iv) Potential Ecological Risk Index Method (PERI) to assess potential environmental risks of jarosite.

\section{MATERIALS AND METHODS}

\section{Sample Collection and Preparation}

The jarosite waste released from Trepça zinc smelter in Mitrovica Industrial Park (MIP), situated in northerneastern Kosovo is considered for the study. MIP is situated very close to the residential area of Mitrovica town, $20 \mathrm{~m}$ next to the banks of Sitnica River. At present tailings in MIP contains over 1.5 million tons of waste, out of which 500 thousand tons of these waste is released from jarosite process of Trepça zinc industry. ${ }^{20,23}$ Within the sampling framework the jarosite samples were collected form open tailing damp. After sampling, jarosite waste was air-dried at room temperature, sieved through $2 \mathrm{~mm}$ size sieve, mixed and homogenized using coning and quartering method and stored in polyethylene containers until analyzed.

\section{Chemical Analysis}

The chemical composition of jarosite samples was determined by treating $0.3 \mathrm{~g}$ sample with $\mathrm{HCl} / \mathrm{HF} / \mathrm{HNO}_{3} /$ $\mathrm{H}_{3} \mathrm{BO}_{3}$ acid mixture digestion method at about $210{ }^{\circ} \mathrm{C}$ until the digested solution was clear. ${ }^{20}$

A modified three-stage (BCR) sequential extraction method (Table 1) was adopted to fractionate heavy metals in acid soluble fraction, reducible fraction, oxi- 
Table 2. Relationship between potential toxicity index $(R)$, potential ecological risk index $\left(E_{f}^{i}\right)$ and pollution level ${ }^{13,14}$

\begin{tabular}{llll}
\hline $\begin{array}{l}\text { Scope of potential ecological } \\
\text { risk index }\left(E_{f}^{i}\right)\end{array}$ & $\begin{array}{l}\text { Ecological risk of single- } \\
\text { factor pollution }\end{array}$ & $\begin{array}{l}\text { Scope of potential } \\
\text { toxicity index }(R)\end{array}$ & $\begin{array}{l}\text { General level of potential } \\
\text { ecological risk }\end{array}$ \\
\hline$E_{f}^{i}<40$ & Low & $R<150$ & Low grade \\
$40 \leq E_{f}^{i}<80$ & Moderate & $150 \leq R<300$ & Moderate \\
$80 \leq E_{f}^{i}<160$ & Higher & $300 \leq R<600$ & Severe \\
$160 \leq E_{f}^{i}<320$ & High & $600 \leq R$ & Serious \\
$320 \leq E_{f}^{i}$ & Serious & & \\
\hline
\end{tabular}

dizable fraction and residual fraction digested from the third stage..$^{20,24}$ After each extraction, the separation was achieved by centrifuging at $3000 \mathrm{rpm}$ for $30 \mathrm{~min}$ and the supernatant was filtered through $0.45 \mu \mathrm{m}$ membranes. The extracts after each extraction step were evaporated to near dryness. Each extract was completed to $5 \mathrm{~mL}$ with $2 \%$ nitric acid. $\mathrm{Zn}, \mathrm{Pb}, \mathrm{Cu}, \mathrm{Cd}$, Ni and As concentration in digested solutions and extracts were analyzed by inductively coupled plasma optical emission spectroscopy (ICP-OES). A Teledyne Leeman Labs (Hudson, NH, USA) Prodigy High Dispersion ICP system is used. The samples were performed in triplicate throughout all the analysis and the results reported were the average values. Blank determination was done using the same reagents as described in the analysis procedure. In order to evaluate the stability and accuracy of the procedure in all samples, the reference material BCR-701 was used with the same procedure.

\section{Leaching Behaviour}

The jarosite samples were characterized for heavy metal leachability according to US EPA Method 1312:1994 Synthetic Precipitation Leaching Procedure (SPLP). ${ }^{21}$ The leaching procedure was as followed: $1 \mathrm{~g}$ (dry weight) of jarosite samples were added to polyethylene bottles and mixed with $50 \mathrm{~mL}$ acid rain (liquid to sol$\mathrm{id}=50: 1)$ in a horizontal shaker at room temperature. Synthetic acid rain extraction fluid was prepared by adding the 60/40 weight percent sulphuric acid and nitric acid to distilled water until the $\mathrm{pH}$ is $3.0 \pm 0.2$. After the planned leaching time, the eluates were filtered using a $0.45 \mu \mathrm{m}$ membrane filter. Heavy metal contents were tested by ICP OES. The samples were also performed in triplicate and the results reported were the average values. All reagents used in this work were analytical or HPLC grade and used without any further purification.

\section{Statistical Analysis}

Principal components analysis (PCA) was carried out to find the relationship between leaching and various speciations. The number of significant principal compo- nents was selected on the basis of Varimax orthogonal rotation with Kaiser Normalisation at eigenvalues greater than 1. The statistical analyses were preceded using Statistica version 10 software.

The Potential Ecological Risk Index Method was used to assess the level of risk of heavy metals from jarosite samples. The assessment of heavy metal contamination was carried out using the Contamination factor $\left(C_{f}^{i}\right) \cdot{ }^{13}$ The design formula is as follows:

$$
C_{f}^{i}=C_{\text {sample }}^{i} / C_{\text {reference }}^{i}
$$

Where $C_{f}^{i} \mathrm{~S}$ is the contamination factor for a single heavy metal; $C_{\text {sample }}^{i}$ is the measured value of the heavy metal in the sample; $C_{\text {reference }}^{i}$ are the parameters for calculation, with reference to the Kosovo standards for heavy metals in soil, ${ }^{22}$ Table 5 . Potential ecological risk factor and potential toxicity response index of heavy metals was estimated in the version suggested by Håkanson ${ }^{14}$ using the following relationship:

$$
E_{f}^{i}=C_{f}^{i} \times T_{f}^{i}
$$

Where $T_{f}^{i}$ is toxic response factor for a given element $(\mathrm{Zn}=1, \mathrm{~Pb}=5, \mathrm{Cd}=30, \mathrm{Cu}=5, \mathrm{Ni}=5, \mathrm{As}=10)$. The sum of the potential ecological risk index $\left(E_{f}^{i}\right)$ all elements examined represent the potential toxicity index of the environment which is calculated as follows:

$$
R=\sum E_{f}^{i}
$$

The evaluation criteria of potential ecological risk of heavy metals are shown in Table 2.

\section{RESULTS AND DISCUSSIONS}

The chemical composition of jarosite waste in Kosovo obtained by ICP-OES is shown in Table 3. As can be seen from the Table 3, iron in form of $\mathrm{Fe}_{2} \mathrm{O}_{3}$ has the 
Table 3. Chemical composition of jarosite sample

\begin{tabular}{cc}
\hline Element & mean $\pm \sigma$ \\
\hline $\mathrm{Al}_{2} \mathrm{O}_{3}, w t . \%$ & $1.42 \pm 0.02$ \\
$\mathrm{Fe}_{2} \mathrm{O}_{3}, w t . \%$ & $44.94 \pm 0.05$ \\
$\mathrm{SiO}_{2}, w t . \%$ & $6.31 \pm 0.7$ \\
$\mathrm{Zn}, w t . \%$ & $10.91 \pm 0.02$ \\
$\mathrm{~Pb}, w t . \%$ & $7.51 \pm 0.13$ \\
$\mathrm{Cu}, w t . \%$ & $0.97 \pm 0.01$ \\
$\mathrm{Ag}, \mathrm{mg} \mathrm{kg}^{-1}$ & $133.82 \pm 11.82$ \\
$\mathrm{Ba}, \mathrm{mg} \mathrm{kg}^{-1}$ & $578.90 \pm 194.73$ \\
$\mathrm{Co}, \mathrm{mg} \mathrm{kg}^{-1}$ & $30.38 \pm 0.27$ \\
$\mathrm{Cd}, \mathrm{mg} \mathrm{kg}^{-1}$ & $2308.69 \pm 24.47$ \\
$\mathrm{Cr}, \mathrm{mg} \mathrm{kg}^{-1}$ & $416.59 \pm 14.35$ \\
$\mathrm{Mn}, \mathrm{mg} \mathrm{kg}^{-1}$ & $6391.71 \pm 84.06$ \\
$\mathrm{Ni}, \mathrm{mg} \mathrm{kg}^{-1}$ & $93.50 \pm 1.10$ \\
$\mathrm{Sr}, \mathrm{mg} \mathrm{kg}^{-1}$ & $156.20 \pm 2.01$ \\
$\mathrm{As}, \mathrm{mg} \mathrm{kg}^{-1}$ & $5075.53 \pm 5.52$ \\
\hline
\end{tabular}

highest content (44.94\%) among all other elements. $\mathrm{SiO}_{2}$ is also important component with $6.31 \%$. The ranges of the total concentration for $\mathrm{Zn}, \mathrm{Pb}$, and $\mathrm{Cu}$ were $10.91 \%$, $7.51 \%$ and $0.97 \%$. In comparison, concentration variations of $\mathrm{Cd}, \mathrm{Ni}, \mathrm{Mn}$ and As were smaller. The ranges of total concentration for $\mathrm{Cd}, \mathrm{Ni}, \mathrm{Mn}$ and As were 2308.69 $\mathrm{mg} / \mathrm{kg}, 93.50 \mathrm{mg} / \mathrm{kg}, 6391.71 \mathrm{mg} / \mathrm{kg}$ and $5075.53 \mathrm{mg} / \mathrm{kg}$, respectively. This observation indicates that the total concentration of heavy metals might be significantly affected by very high or low values. Therefore, the average concentration was used here to describe the characteristic of heavy metal in jarosite waste. As a whole, the total concentrations of $\mathrm{Zn}$ and $\mathrm{Pb}$ were much higher than that of $\mathrm{Cu}, \mathrm{Cd}, \mathrm{Ni}, \mathrm{Mn}$ and As. Lower concentrations of elements such as $\mathrm{Co}, \mathrm{Cr}, \mathrm{Ba}, \mathrm{Sr}$ and $\mathrm{Ag}$ were recorded as well. The high total content of $\mathrm{Pb}$ and $\mathrm{Zn}$ in jarosite is contributed to chemical speciation of these two heavy metals formed during the zinc extraction process.

A modified three-stage sequential extraction method was used to characterize the chemical speciation of heavy metals in jarosite waste in this study. The extracted fractions were exchangeable and acid soluble fraction, reducible fraction, oxidizable fraction and residual fraction, which were correspondingly noted as F1, F2, F3 and F4. As shown in Table 4, Zn showed the highest proportion of F1 fraction with an average of $2224.05 \mathrm{mg} / \mathrm{kg}$. The analyzed jarosite samples contained F1 fraction for $\mathrm{Cd} 14.76 \mathrm{mg} / \mathrm{kg}, \mathrm{Cu} 19.33 \mathrm{mg} / \mathrm{kg}$, Ni $1.05 \mathrm{mg} / \mathrm{kg}$, while the lowest proportion of F1 fraction was for As is $0.44 \mathrm{mg} / \mathrm{kg}$ and $\mathrm{Pb}$. The results show that apart from $\mathrm{Zn}$ all other heavy metals in F1 fraction were considered as having a weak binding and a weak potential bioavailability and leaching ability. The aver-
Table 4. The mean values of SPLP and three stage BCR sequential extraction of jarosite sample

\begin{tabular}{|c|c|c|c|}
\hline \multirow[t]{2}{*}{ Elements } & \multirow[t]{2}{*}{$\begin{array}{c}\text { SPLP } \\
\left(\mathrm{mg} \mathrm{kg}^{-1}\right)\end{array}$} & \multicolumn{2}{|c|}{$\begin{array}{c}\text { BCR } \\
\left(\mathrm{mg} \mathrm{kg}^{-1}\right)\end{array}$} \\
\hline & & F1 & 14.76 \\
\hline \multirow{3}{*}{$\mathrm{Cd}$} & \multirow{3}{*}{63.79} & $\mathrm{~F} 2$ & 10.22 \\
\hline & & F3 & 20.56 \\
\hline & & F4 & 861.60 \\
\hline \multirow{4}{*}{$\mathrm{Cu}$} & \multirow{4}{*}{133.66} & $\overline{F 1}$ & 28.82 \\
\hline & & $\mathrm{F} 2$ & 1055.1 \\
\hline & & $\mathrm{F} 3$ & 104.32 \\
\hline & & $\mathrm{F} 4$ & 4270.13 \\
\hline \multirow{4}{*}{$\mathrm{Ni}$} & \multirow{4}{*}{3.02} & F1 & 1.08 \\
\hline & & $\mathrm{F} 2$ & 1.12 \\
\hline & & F3 & 0.79 \\
\hline & & $\mathrm{F} 4$ & 52.52 \\
\hline \multirow{4}{*}{$\mathrm{Pb}$} & \multirow{4}{*}{120.00} & F1 & 0.00 \\
\hline & & $\mathrm{F} 2$ & 11700.3 \\
\hline & & F3 & 11339.8 \\
\hline & & $\mathrm{F} 4$ & 39426.55 \\
\hline \multirow{4}{*}{$\mathrm{Zn}$} & \multirow{4}{*}{4901.83} & F1 & 2162.09 \\
\hline & & $\mathrm{F} 2$ & 3841.61 \\
\hline & & F3 & 5233.25 \\
\hline & & $\mathrm{F} 4$ & 63311.19 \\
\hline \multirow{4}{*}{ As } & \multirow{4}{*}{0.45} & F1 & 0.44 \\
\hline & & $\mathrm{F} 2$ & 12.99 \\
\hline & & F3 & 0.96 \\
\hline & & F4 & 5061.04 \\
\hline
\end{tabular}

F1: Exchangeable/Acid-soluble fraction; F2: reducible fraction; F3: oxidizable fraction; F4: residual fraction. The results presents mean of triplicate samples.

age of $\mathrm{F} 2$ fraction for $\mathrm{Pb}, \mathrm{Zn}$ and $\mathrm{Cu}$ was 11700.3 $\mathrm{mg} / \mathrm{kg}, 3841.61 \mathrm{mg} / \mathrm{kg}$ and $1055.1 \mathrm{mg} / \mathrm{kg}$, respectively. In comparison, F2 fraction for $\mathrm{Cd}$ was close to that for As. F2 fraction for Ni was the lowest in all six metals, and the average was $1.12 \mathrm{mg} / \mathrm{kg}$. Ni and As had an approximate proportion in F3 fraction. The highest values were observed in $\mathrm{Pb}$ with an average of 11339.8 $\mathrm{mg} / \mathrm{kg}$ and $\mathrm{Zn}$ with $5233.25 \mathrm{mg} / \mathrm{kg}$. Meanwhile, $\mathrm{Cd}$ showed the proportion of F3 fraction with an average of $20.56 \mathrm{mg} / \mathrm{kg}$ and $\mathrm{Cu}$ with $104.32 \mathrm{mg} / \mathrm{kg}$. In contrast, $\mathrm{Zn}$, $\mathrm{Pb}, \mathrm{Cu}, \mathrm{As}, \mathrm{Cd}$ and $\mathrm{Ni}$ were quite high in $\mathrm{F} 4$ fraction with their average values of $63311.19 \mathrm{mg} / \mathrm{kg}, 39426.55$ $\mathrm{mg} / \mathrm{kg}, 4270.13 \mathrm{mg} / \mathrm{kg}, 5061.04 \mathrm{mg} / \mathrm{kg}, 861.60 \mathrm{mg} / \mathrm{kg}$ and $52.52 \mathrm{mg} / \mathrm{kg}$, respectively. The highest values of heavy metals in F4 fraction shows that the F4 was the most difficult fraction to leach under natural conditions. Kruger et al., ${ }^{25}$ confirmed that heavy metals in F1 fraction represent a small fraction of the total metal content present in soil samples. Thus, the authors reported that this fraction generally accounted for less than $2 \%$ of the total metals in soil samples, while in our case this fraction generally presents $0.24 \%$ of the total metal content. 


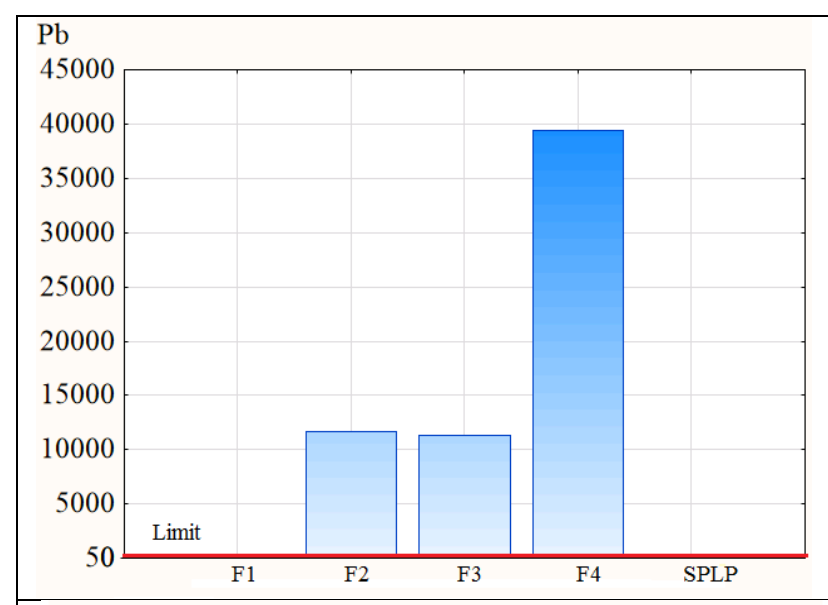

$\mathrm{Ni}$
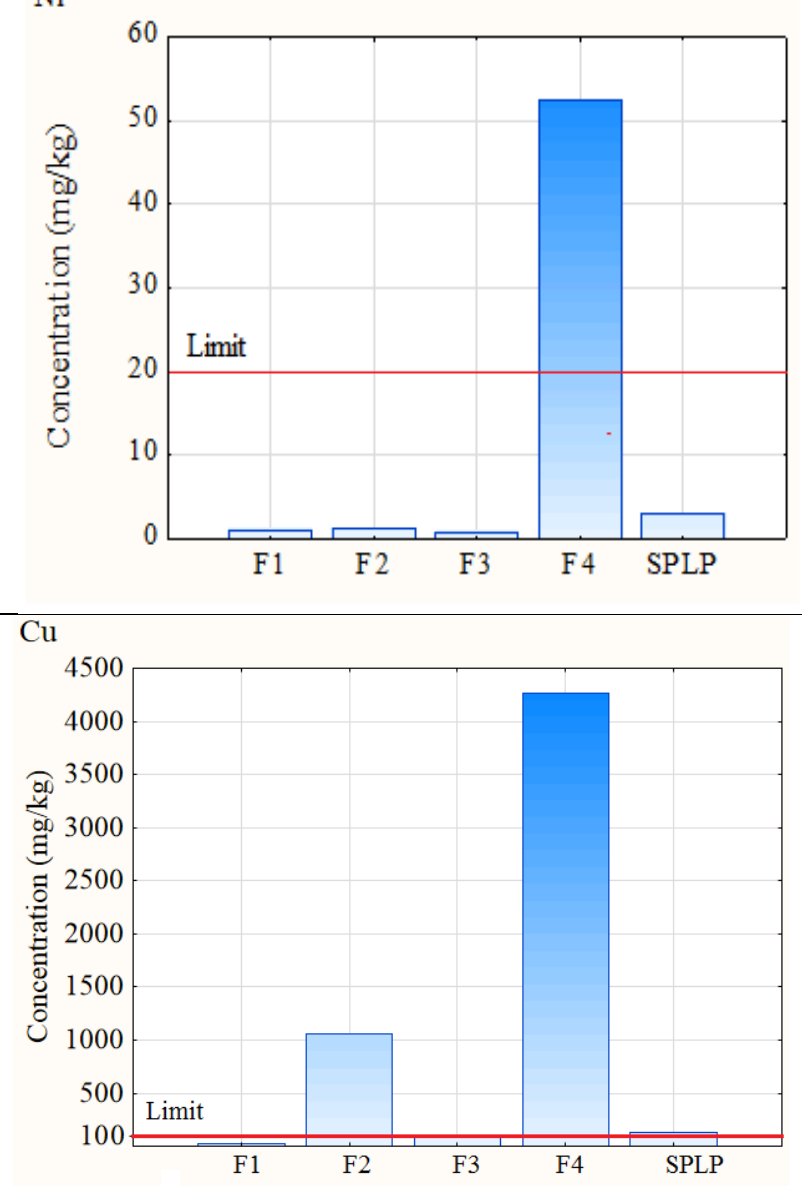

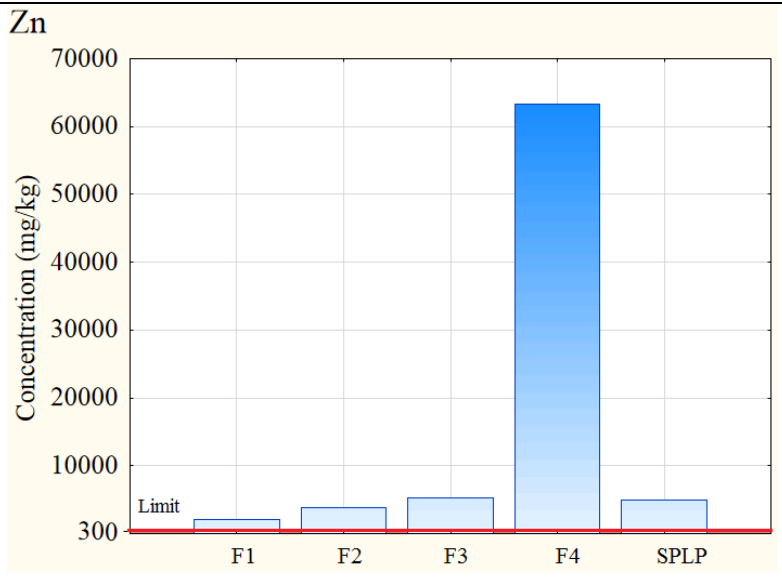

$\mathrm{Cd}$
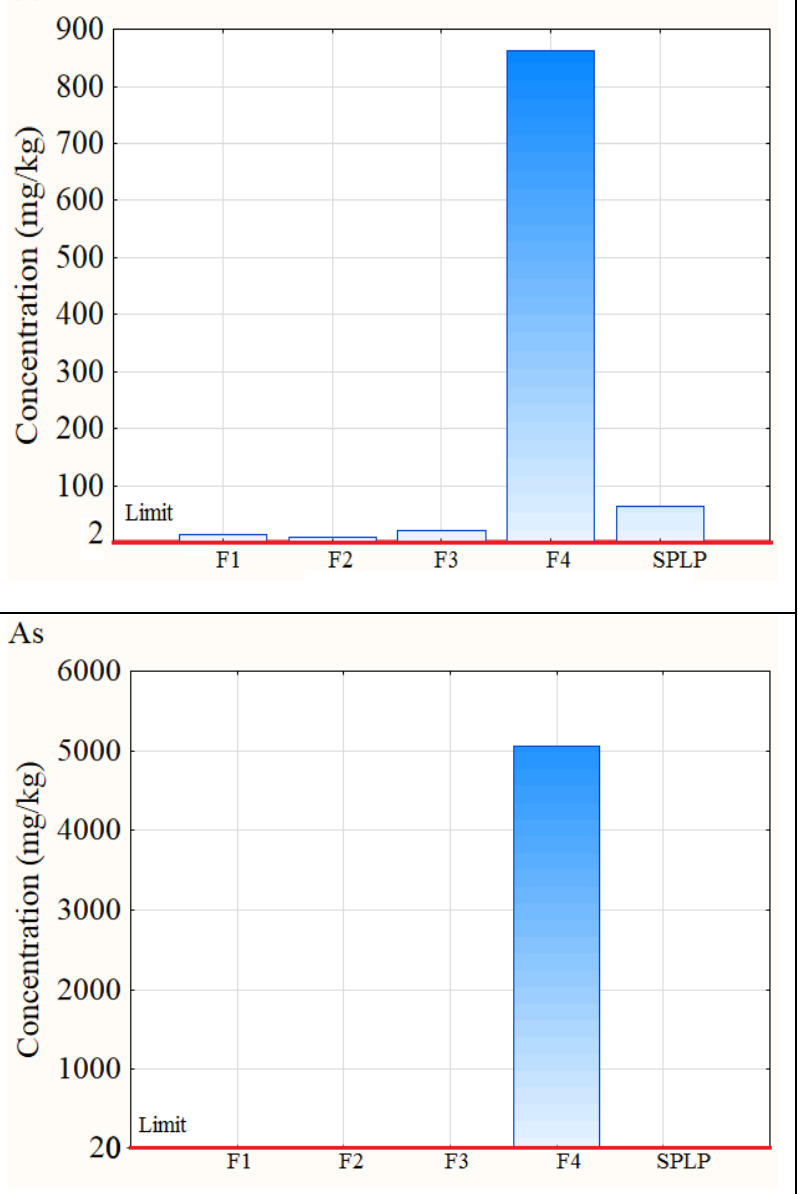

Figure 1. Leaching amount and speciation in each fraction of heavy metals in jarosite waste (the horizontal red line means corresponding standard limits).

US EPA SPLP test is a common method to predict possible leaching of heavy metals in different environmental media. Figure 1. shows the leaching amount of heavy metals in jarosite samples by SPLP. Kosovo standard limits for heavy metals in soil ${ }^{22}$ were employed as supplementary in the study. As shown in Table 4, the leaching concentration of $\mathrm{Cd}$ was $63.79 \mathrm{mg} / \mathrm{kg}$, where the amount of leached $\mathrm{Cd}$ is more than $2.0 \mathrm{mg} / \mathrm{kg}$ of the regulated limit. $\mathrm{Cu}$ had a SPLP leaching amount higher than $100 \mathrm{mg} / \mathrm{kg}$ of the regulatory limit. The leaching concentrations of $\mathrm{Ni}$ and $\mathrm{As}$ in jarosite samples were also smaller than $50 \mathrm{mg} / \mathrm{kg}$ of Ni regulatory limits and $20 \mathrm{mg} / \mathrm{kg}$ of As regulatory limits. This result soundly established that SPLP leaching value did not have a fixed relationship with total concentration of heavy metals. 


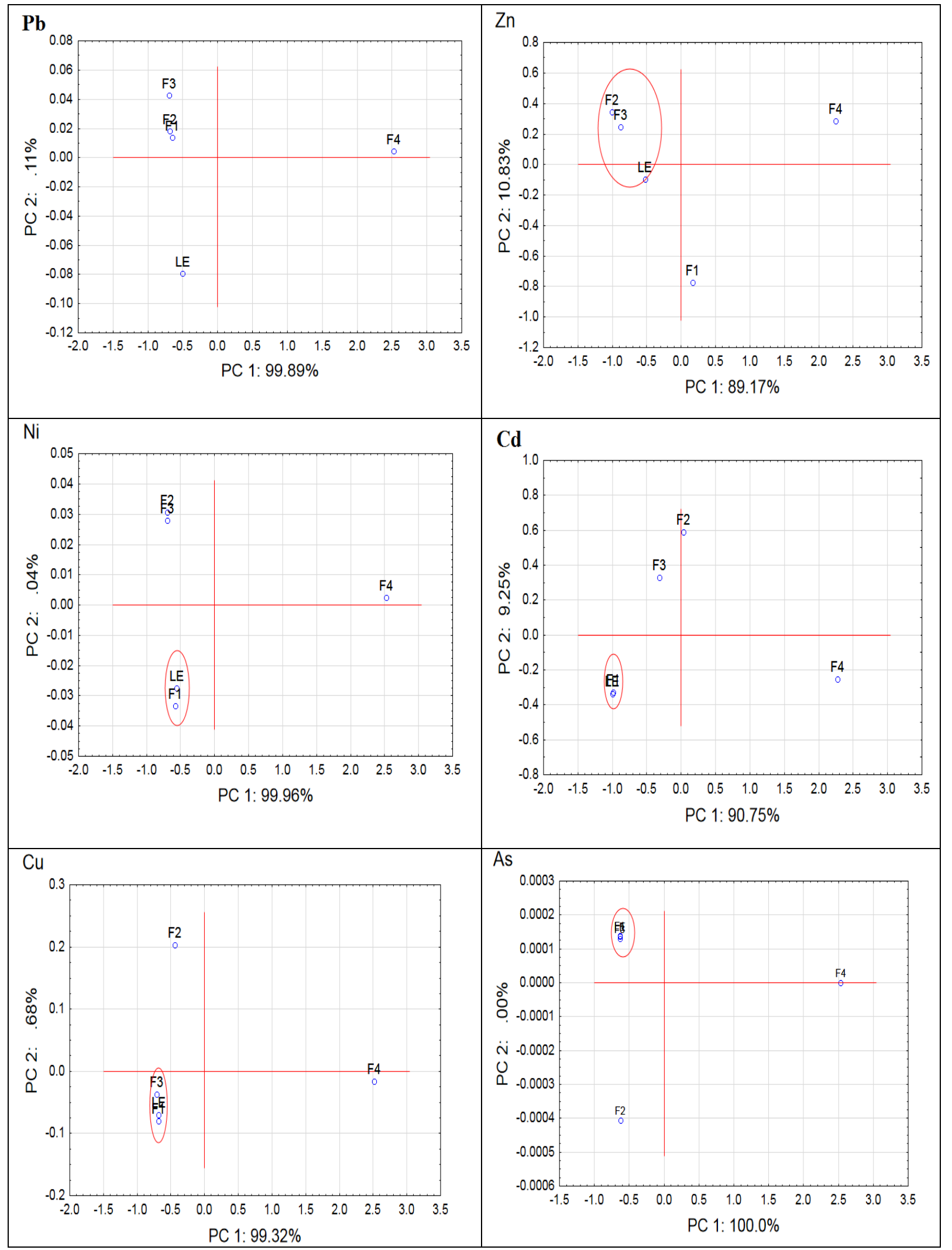

Figure 2. Principal components analysis (PCA) results of SPLP leaching (LE) and BCR sequential extraction fractions for $\mathrm{Pb}, \mathrm{Zn}$, $\mathrm{Ni}, \mathrm{Cd}, \mathrm{Cu}$ and As. 
Table 5. Potential ecological risk assessment results of metals present in jarosite waste

\begin{tabular}{|c|c|c|c|c|c|c|c|}
\hline & Element & $\frac{C_{\text {sample }}^{i}}{\mathrm{mg} \mathrm{kg}^{-1}}$ & $\frac{C_{\text {reference }}^{i}}{\mathrm{mg} \mathrm{kg}^{-1}}$ & $C_{f}^{i}$ & $T_{f}^{i}$ & $E_{f}^{i}=C_{f}^{i} \times T_{f}^{i}$ & $R=\sum E_{f}^{i}$ \\
\hline \multirow{6}{*}{ SPLP } & $\mathrm{Cd}$ & 63.79 & 2 & 21.26 & 31.8 & 676 & \multirow[t]{6}{*}{711.5} \\
\hline & $\mathrm{Zn}$ & 4901.83 & 300 & 16.33 & 1 & 16.33 & \\
\hline & $\mathrm{Cu}$ & 133.67 & 100 & 1.33 & 5 & 6.65 & \\
\hline & $\mathrm{Ni}$ & 3.02 & 50 & 0.06 & 5 & 0.3 & \\
\hline & $\mathrm{Pb}$ & 120.00 & 50 & 2.4 & 5 & 12 & \\
\hline & As & 0.45 & 20 & 0.02 & 10 & 0.22 & \\
\hline \multirow{5}{*}{ BCR (F1) } & $\mathrm{Cd}$ & 14.76 & 2 & 7.38 & 30 & 221.4 & \multirow[t]{5}{*}{230.37} \\
\hline & $\mathrm{Zn}$ & 2162.09 & 300 & 7.206 & 1 & 7.206 & \\
\hline & $\mathrm{Cu}$ & 28.82 & 100 & 0.28 & 5 & 1.441 & \\
\hline & $\mathrm{Ni}$ & 1.08 & 50 & 0.021 & 5 & 0.108 & \\
\hline & As & 0.44 & 20 & 0.022 & 10 & 0.22 & \\
\hline
\end{tabular}

SPLP: Synthetic Precipitation Leaching Procedure, BCR (F1): BCR exchangeable fraction

On the other hand, the leaching concentration of $\mathrm{Pb}$ and $\mathrm{Zn}$ in jarosite sample exceeded the limits. For $\mathrm{Pb}$, the leaching concentration was $133.66 \mathrm{mg} / \mathrm{kg}$, compared to the regulatory limit of $50 \mathrm{mg} / \mathrm{kg}$. The leaching concentration of $\mathrm{Zn}$ was $4901.83 \mathrm{mg} / \mathrm{kg}$. The excess of $\mathrm{Zn}$ leaching amount over the regulatory limits of 300 $\mathrm{mg} / \mathrm{kg}$ observed in jarosite samples suggested that $\mathrm{Zn}$ had the strongest mobility, followed by $\mathrm{Pb}, \mathrm{Cu}$ and $\mathrm{Cd}$. Based on the above sequential extraction and leaching results, something interesting could be found. For an instance, $\mathrm{Pb}$ had a total content of $7.51 \%, 120 \mathrm{mg} / \mathrm{kg}$ leaching amount and no proportion in F1 fraction. Further, it was observed that $\mathrm{Pb}$ had a high proportion in $\mathrm{F} 2$ and $\mathrm{F} 3$ fractions.

Principle components analysis (PCA) was applied to evaluate the possible relevance between chemical speciation and leaching toxicity. The dataset used in PCA were collected from the results of sequential extraction procedure and leaching test. The variables were the concentration of heavy metals in modified BCR extraction speciations (F1, F2, F3 and F4) and SPLP leaching (LE). LE means the ratio of leaching concentration to standard SPLP method, describing the degree of leaching ability for $\mathrm{Zn}, \mathrm{Pb}, \mathrm{Cu}, \mathrm{Cd}, \mathrm{Ni}$ and As. Two principal components (PC1 and $\mathrm{PC} 2$ ) were extracted through PCA for each metal. As shown in Figure 2, the location of speciation and LE in the graph determined the relevance among these variables. It was suggested that the location in the same scope showed the most closely relevance. Obviously, for $\mathrm{Ni}, \mathrm{Cu}$, and $\mathrm{Cd}$, the LE was well in accordance with F1. Thus, the proportion of $\mathrm{Ni}, \mathrm{Cu}$ and $\mathrm{Cd}$ were leached into the acid (LE) and bio-available fraction (water/acid soluble fraction, i.e. F1). Whereas, As showed significant correlation between LE, F1 and F3 fractions. As in leaching toxici- ty and acid-soluble form (F1) had almost the same potential of mobility and availability. While, in F3 there are also, concentrations of As in the reducible fractions associated with $\mathrm{Fe}$ and $\mathrm{Mn}$ oxy-hydroxides. On the other hand, for $\mathrm{Zn}$, the LE was in close relevance with F2 and F3 fractions. Zn is marked in the jarosite samples by a high potential of bioavailability, especially in oxidizable and reducible fractions with high concentration. The speciation of $\mathrm{Zn}$ in F2 and F3 reflects the dissolution of sulphides (sphalerite) and adsorption and co-precipitation with Fe oxides. However, no distinct connection was obtained among the LE and speciation for $\mathrm{Pb}$. Due to the low leaching rate and $\mathrm{Pb}$ speciation in F1 (concentration rate set to zero), it may be unnecessary to pay more attention.

Nevertheless, using component analysis, we obtained a statistically highly significant correlation between metal speciation and acid leachability. These findings could be important for building future models predicting the bioavailability, mobility and leachability of heavy metals in jarosite waste. Such models could be of a great importance for utilization of jarosite waste.

In order to assess the environmental risk of heavy metals present in jarosite tailing waste, individual contamination factor $\left(C_{f}^{i}\right)$ of elements was calculated. In this study, $C_{f}^{i}$ was calculated as a fraction of exchangeable and acid-soluble (F1) with the reference to Kosovo limits of heavy metals in soil. ${ }^{22}$ The results of SPLP and F1 were selected since other researchers confirmed that the exchangeable and acid-soluble form were the direct phases that polluted the environment. ${ }^{26-29}$ Min et al. ${ }^{13}$ suggested that total metal content of heavy metals provides inadequate information about the toxicity or bioavailability. ${ }^{25,30}$ PERI results (Table 5) showed that leaching of metals under acidic conditions present the 
direct form that pollutes the environment. PERI results suggested that $\mathrm{Cd}$ in jarosite waste was the main risk source. As shown in Table 5, there were about high to very high risk class due to the high PERI values of $\mathrm{Cd}$. $\mathrm{Zn}$ and $\mathrm{Pb}$ also exhibited low PERI values varied from 7.2 to 16.3. In addition, $\mathrm{Cu}, \mathrm{Ni}$ and $\mathrm{As}$ showed no risk class.

In general, the calculated PERI values under SPLP conditions showed serious ecological risk $(600 \leq R)$ with 711.5. The scope of potential toxicity index of the elements extracted on $\mathrm{F} 1$ have moderate ecological risk $(150 \leq R<300)$ with 230.37 .

In general, PERI results showed that not only the high content heavy metals $\mathrm{Zn}$ and $\mathrm{Pb}$, but also some low content heavy metal $\mathrm{Cd}$ posed potential risks to the environment because of their proportion in acid soluble fraction and toxic response factor.

\section{CONCLUSION}

Jarosite waste in Kosovo was investigated to determine the characteristics, leaching behavior and ecological risks of heavy metals. The content of analyzed heavy metals in jarosite decreased in the order $\mathrm{Zn}>\mathrm{Pb}>\mathrm{Cu}$ $>\mathrm{As}>\mathrm{Cd}>\mathrm{Ni}$. The predominant speciation of $\mathrm{Cd}$ was $\mathrm{F} 1$ and $\mathrm{F} 3$ fraction. Although $\mathrm{Pb}$ had no proportion in $\mathrm{F} 1$ fraction, it had relatively high proportion in F2 and F3 fraction. F4 fraction was the major speciation for all analyzed metals. The leaching concentration of $\mathrm{Zn}, \mathrm{Cd}$, $\mathrm{Cu}$ and $\mathrm{Pb}$ also exceeded the standard limits. However, the SPLP leaching concentrations of $\mathrm{Ni}$ and As were under the standard limits. The close relevance of SPLP leaching toxicity and F1 fraction was observed in $\mathrm{Zn}$, $\mathrm{Cu}, \mathrm{Cd}, \mathrm{Ni}$ and As by PCA method. No close relevance was obtained among the LE and speciation for Pb. Furthermore, PERI results showed that $\mathrm{Zn}$ has the highest contamination factor, while $\mathrm{Cd}$ posed very high ecological risk to the environment due to the high toxic response factor.

\section{REFERENCES}

1. F. Siegel, Environmental geochemistry of potentially toxic metals, Springer - Verlag Berlin Heidelberg, 2000, p. 1-59.

2. J. S. Yang, J. Y. Lee, K. Baek, T. S. Kwon, and J. Choi, J. Hazard. Mater. 171 (2009) 443-451.
3. M. Pelino, Waste Manage. 20 (2000) 561-568.

4. A. Pappu, M. Saxena, and Sh. R. Asolekar, Sci. Total Environ. 359 (2005) 232-243.

5. A. Pappu, M. Saxena, and Sh. R. Asolekar, J. Hazard. Mater. 137 (2006) 1589-1599.

6. J. Lee and B. Dh. Pandey, Waste Manage. 32 (2012) 3-18.

7. M. P. Asta, J. Cama, M. Martnez, and J. Gimnez, J. Hazard. Mater. 171 (2009) 965-972.

8. G. Zhao-hui, P. Feng-kai, X. Xi-yuan, Zh. Long, and J. Kaiqi, Trans. Nonferrous. Met. Soc. China 20 (2010) 2000-2005

9. S. Dulca and D. C. Adriano, J. Environ. Qual. 26 (1997) 590 602 .

10. A. Kim and P. Hesbach, Fuel 88 (2009) 926-937.

11. A. Tessier, P. G. C. Campbell, and M. Bisson, Anal. Chem. 51 (1979) 844-850.

12. G. Rauret, J. F. Lopez-Sanchez, A. Sahuquillo, R. Rubio, C. Davidson, and A. Ure, J. Environ. Monit. 1 (1999) 57-61.

13. X. Min, X. Xie, L. Chai, Y. Liang, M. Li, and Y. Ke, Trans. Nonferrous. Met. Soc. China 23 (2013) 208-218.

14. L. Håkanson, Water Res. 14 (1980) 975-1001.

15. H. Zhu, X. Yuan, G. Zeng, M. Jiang, J. Liang, C. Zhang, J. Yin, H. Huang, Z. Liu, and H. Jiang, Trans. Nonferrous. Met. Soc. China 22 (2012) 1470-1477.

16. L. A. Maranho, I. Abreu, R. Santelli, R. C. Cordeiro, A. SoaresGomes, L. B. Moreiras, R. D. Morais, and D. M. S. Abessat, J. Coast. Res. 56 (2009) 851-855.

17. G. Qingjie and D. Jun, J. Chin. Uni. Geosci. 3 (2008) 230-241.

18. I. Gergen and M. Harmanescu, Chem. Central J. 6 (2012) 156.

19. Zh. Wei, D. Wang, H. H. Zhou, and Zh. QI, Proc. Environ. Sci. 10 (2011) 1946-1952.

20. M. Kerolli-Mustafa, H. Fajković, S. Rončević, and L. Ćurković. J. Geochem. Explor. 148 (2015) 161-168.

21. U.S. EPA Synthetic Precipitation Leaching Procedure (SPLP) Method 1312: 1994.

22. Kosovo Government (2009) Administrative Instruction in Allowing Norms of Hazardous Substances and Harmful Presence in Soil, Annex 1 .

23. M. Kerolli-Mustafa, I. Bačić, and L. Ćurković, Materialwiss. Werkstofftech. 4 (2013) 768-773.

24. E. Margui, V. Salvado, and I. Queralt, Anal. Chim. Acta 524 (2004) 151-159.

25. O. Kruger, U. Kalbe, W. Berger, F. G. Simon, and S. L. Meza, J. Hazard. Mater. 207 (2012) 51-55.

26. P. Grathwohl and B. Susset, Waste Manage. 29 (2009) 26812688.

27. Y. Nathan, M. Dvorachek, I. Pelly, and U. Mimran, Fuel 78 (1999) 205-213.

28. Y. J. Feng, Y. Q. Yang, Ch. Zh. Er-Xi Song, D. Sh. Shen, and Y. Y. Long, Waste Manage. 33 (2013) 1073-1078.

29. G. Jegadeesan, S. R. Al-Abed, and P. Pinto, Fuel 87 (2008) 1887-1893.

30. R. D. Doepker and W. K. O'Connor, Mine Water Environ. 10 (1991) 73-92. 